DOI: https://doi.org/10.30749/2594-8261.v5n1p34-65

\title{
TRABALHO DOMÉSTICO E MULHERES: UMA ANÁLISE SOBRE COMO A REFORMA TRIBUTÁRIA PODE CONTRIBUIR PARA A REDUÇÃO DAS DESIGUALDADES DE GÊNERO
}

\section{HOUSEWORK AND WOMEN: AN ANALYSIS ON HOW TAX REFORM CAN CONTRIBUTE TO REDUCING GENDER INEQUALITIES}

\section{Alessandra Soares Freixo* Camilla Cavalcanti Rodrigues Cabral ${ }^{\star *}$}

Resumo: $O$ presente trabalho tem como objetivo apresentar reflexões sobre as desigualdades de gênero associadas à função social e econômica do trabalho em âmbito doméstico, bem como apontar mecanismos para promoção de políticas públicas inclusivas através da adoção de um sistema tributário de caráter redistributivo. Partindo de uma análise sobre a tributação no Brasil, a pesquisa objetiva indicar possíveis caminhos para a consecução de justiça fiscal, via reforma tributária, para viabilizar a implementação de políticas de cunho social para a inclusão econômica das mulheres que desempenham trabalho em âmbito doméstico.

Palavras-chave: Trabalho doméstico. Desigualdade de gênero. Tributação. Reforma Tributária.

\begin{abstract}
The goal of the present work is to present reflections about gender inequalities associated with the social and economic function of the housework, as well as pointing out mechanisms to promote inclusive public policies through the adoption of a redistributive tax system. Starting from an analysis of taxation in Brazil, the research aims at pointing out possible directions for the achievement of tax justice, through tax reform, in order to allow the implementation of social policies for the economic inclusion of women that engage in housework.
\end{abstract}

Keywords: Housework. Gender Inequalities. Taxation. Tax Reform.

Recebido em: 31/03/2021. Aceito em: 30/04/2021.

\footnotetext{
* Doutoranda no Programa de Pós-Graduação da Universidade de São Paulo. E-mail: alessandra.sfreixo@gmail.com.

** Bacharelado em Direito pela Faculdade de Direito da Universidade Federal de Pernambuco (FDR/UFPE). Procuradora da Fazenda Nacional de Primeira Categoria. E-mail: camilla_cabral@hotmail.com.
} 


\section{INTRODUÇÃo}

A desigualdade de renda manifesta-se em praticamente todos os países, atingindo mais de $70 \%$ da população mundial. Se realizado um recorte de gênero ${ }^{1}$, observa-se que os homens detêm $50 \%$ a mais de riqueza do que as mulheres, conforme aponta o relatório "Tempo de Cuidar", da Oxfam Brasil, o que significa que estas compõem substancialmente os grupos de baixa renda.

A ideia de gênero como uma divisão social enfatiza que essas diferenças são um produto de origem histórica e estrutural, de modo que, pela forma de construção da sociedade, observam-se sensíveis desigualdades, a exemplo da baixa representatividade feminina na política, no acesso ao mercado de trabalho e, sobretudo, na maior participação de mulheres na realização das tarefas domésticas.

A estrutura social contribui para a permanência da desigualdade de gênero, ao atribuir preponderantemente à mulher a realização dos afazeres domésticos e 0 cuidado com filhos e parentes, responsáveis por $75 \%$ de todo o trabalho de cuidado não remunerado no mundo, em tarefas que agregam pelo menos US\$10,8 trilhões à economia por ano, benefício financeiro que reverte para os mais ricos, em grande parte homens. Ademais, em todo o mundo, $42 \%$ das mulheres em idade ativa estão fora do mercado de trabalho, frente a $6 \%$ dos homens, o que se deve, segundo aponta 0 estudo, às responsabilidades não remuneradas pela prestação do cuidado.

$E$ ainda que se fale em trabalho doméstico remunerado e acesso ao mercado de trabalho, a situação de vulnerabilidade e desigualdade de gênero persiste. Conforme estimativa da Organização Internacional do Trabalho (OIT), em 12 de junho de 2020, na América Latina e no Caribe, entre 11 e 18 milhões de pessoas se dedicam ao trabalho doméstico remunerado, sendo $93 \%$ composto por mulheres, e dentro desse percentual, mais de $77,5 \%$ atuam em situação de informalidade, sem acesso à proteção social, a exemplo dos direitos trabalhistas e previdenciários.

Atrelado a isso, a pandemia do novo coronavírus exacerbou desigualdades sociais e econômicas já existentes, das quais a desigualdade de gênero é um aspecto digno de nota. Importa destacar que a OXFAM publicou, em janeiro de 2021, o

\footnotetext{
${ }^{1}$ Será adotado o conceito binário de gênero, ou seja, mulher/ feminino e homem/masculino.
} 
Relatório intitulado The inequality virus (BERKHOUT et al., 2021), que aponta para o crescimento das desigualdades de gênero. Segundo o referido documento, no primeiro mês da pandemia, em todo o mundo, a renda das mulheres que trabalham na economia informal - cerca de 740 milhões de mulheres - caiu $60 \%$, sendo o desemprego um fator que afeta desproporcionalmente as mulheres, pela feminização de determinados setores de serviço, como o turismo, por exemplo.

Partindo de um diagnóstico que indica o efetivo aumento de concentração de renda e a elevação do contingente populacional que vive na pobreza, durante 0 ano de 2020, o Relatório aponta para a necessidade de tributação dos denominados superricos, como contrapartida arrecadatória para implementação de políticas públicas de caráter redistributivo.

E sendo certo que a tributação é o principal instrumento que o Estado dispõe para financiamento de políticas sociais, prestação de serviços públicos e intervenção na ordem social e econômica, o tema da justiça fiscal foi recuperado por estudiosos que enxergam no sistema tributário um mecanismo de correção das disparidades inerentes ao próprio capitalismo.

Num cenário de incertezas sobre os impactos econômicos gerados pela pandemia do novo coronavírus, o papel do Estado no enfrentamento de uma crise sanitária sem precedentes está no cerne dos debates contemporâneos acerca dos gastos públicos.

No que diz respeito ao papel de proteção desempenhado pelo Estado, num contexto de bem-estar social preconizado pela Constituição de 1988 (BRASIL, 1988), estudos recentes apontam para a necessidade de uma reforma tributária comprometida com a redução da expressiva desigualdade social existente no Brasil, como forma de implementar uma política redistributiva de renda. Essa questão se mostra de extrema relevância para o debate acerca dos caminhos que devem ser adotados pelo Estado para garantir uma rede de segurança social para enfrentamento dos impactos dessa crise, sentidos de maneira mais gravosa pela população mais vulnerável, sobretudo pelas mulheres.

No Brasil, as discussões sobre a questão tributária foram retomadas em meados de 2019, acompanhada de outras pautas relevantes, como a reforma 
previdenciária e administrativa. Contudo, as propostas de reforma tributária apresentadas até o momento - PEC № 45/2019, em trâmite perante a Câmara dos Deputados e PEC oํ 110/2019, em trâmite perante o Senado Federal - dissociam-se de um plano fundado na ordem social, uma vez que não intentam conciliar a dicotomia crescimento econômico/redução de desigualdades sociais a partir da viável tributação direta de renda e patrimônio.

Estudos recentes apontam para os mecanismos de perpetuação de desigualdades sociais presentes na legislação brasileira que regulamenta a tributação sobre a renda e patrimônio. Soma-se a isso a ênfase dada à tributação indireta, incidente sobre a produção e o consumo, que tem um caráter sabidamente regressivo, na medida em que repassa igualmente a todos os consumidores o ônus da tributação, sem critérios de distinção de renda.

Portanto, muito embora a tributação não seja direta e primordialmente responsável pelas desigualdades de gênero, analisar a sua importância pela perspectiva dos direitos humanos e da justiça fiscal pode ser um mecanismo para a redução das disparidades e consecução das políticas públicas voltadas para as mulheres, sobretudo as que exercem as suas atividades em âmbito doméstico.

\section{DESIGUALDADE DE GÊNERO, TRABALHO DOMÉSTICO E O MAIOR IMPACTO PARA AS MULHERES}

A desigualdade econômica vem crescendo de forma exponencial. Conforme Relatório da OXFAM Brasil, intitulado Tempo de Cuidar: o trabalho de cuidado não remunerado e mal pago e a crise global da desigualdade (OXFAM BRASIL, 2020), em 2019, os bilionários do mundo eram apenas 2.153 indivíduos e detinham mais riqueza do que 4,6 bilhões de pessoas. O relatório ainda constatou que os homens detêm 50\% a mais de riqueza do que as mulheres no mundo, situação que se deve, em grande medida, à prestação dos serviços de cuidado.

O trabalho de cuidado com crianças, parentes em situação de vulnerabilidade e a execução dos afazeres domésticos são necessidades básicas e decorrem dos processos de socialização, essenciais à sobrevivência e imprescindíveis à economia. Para George e Santos (2014, p. 54), a "disposição de cuidar" associa-se à construção 
de papéis de gênero em que se naturaliza a disposição ao cuidado como uma propensão feminina, baseada em sua função reprodutiva.

O conceito de gênero é explicado por Lerner (2019, p. 35) como uma definição cultural de comportamento aprovado aos sexos em determinada sociedade de uma época específica, produto cultural que varia ao longo do tempo. Não há, portanto, razões biológicas para determinar diferenças econômicas, culturais ou de poder entre homens e mulheres.

Entretanto, as divisões sexuais do trabalho manifestam-se na relação entre o trabalho produtivo remunerado e o trabalho produtivo não remunerado, e identificam a mulher como responsável pelos trabalhos de cuidado, muitas vezes sob a justificativa da maternidade e posse de atributos mais adequados e inatos para as tarefas, enquanto os homens seriam incumbidos do trabalho remunerado. Conforme Küchemann e Pfeilsticker (2012),

(...) historicamente, coube às mulheres principalmente a responsabilidade sobre as tarefas reprodutivas, enquanto aos homens foram delegadas as tarefas produtivas, pelas quais passaram a receber uma remuneração. As construções culturais transformaram essa divisão sexual do trabalho em uma especialização "natural". Além disso, o papel de esposa e mãe foi mistificado: o fato de que as mulheres se dedicassem somente ao lar se transformou em um símbolo de status e gerou-se um culto à domesticidade, no qual a família e o domicílio passaram a ser considerados espaços de afeto e criação a cargo delas (KÜCHEMANN; PFEILSTICKER, 2012, p. 3-4).

Federici (2017, p. 119) aponta que a divisão sexual do trabalho é intrínseca ao capitalismo, de modo que se encontra presente desde os seus primórdios, na forma como o sistema se organizou. A autora destaca que a acumulação primitiva do trabalho também foi uma acumulação de diferenças dentro da classe trabalhadora, em que as hierarquias construídas sobre o gênero, assim como sobre a raça e a idade, se tornaram constitutivas da dominação de classe e da formação do proletariado.

Portanto, a estrutura social patriarcal e capitalista contribuem para o aumento da desigualdade de gênero, ao atribuir preponderantemente à mulher a realização dos afazeres domésticos e o cuidado com filhos e parentes, tarefas muitas vezes não encaradas como trabalho efetivamente.

Ao exercício do trabalho doméstico não remunerado foi cunhado o termo Economia do Cuidado, para se referir à imposição social às mulheres da criação dos filhos, 
cuidado com parentes idosos e gerenciamento dos afazeres domésticos sem que as tarefas exercidas e o tempo demandado sejam financeiramente recompensados, reconhecidos ou apoiados.

O trabalho de cuidado enquanto atividade permanece invisibilizado por não possuir ciclos de acumulação, não estabelecer relações assalariadas e ser difícil precificá-lo. Portanto, "a falta de valoração monetária do trabalho doméstico não remunerado impede de avaliar a real contribuição econômica das mulheres" (ARRIAGADA, 2007, p. 244).

Conforme mensurado pela Oxfam Brasil (2020), as mulheres executam 75\% de todo o trabalho de cuidado não remunerado no mundo, em tarefas que agregam pelo menos US\$10,8 trilhões à economia por ano, montante três vezes superior ao estimado para todo o setor de tecnologia do mundo, benefício financeiro que reverte para os mais ricos, em grande parte homens. Ademais, em todo o mundo, $42 \%$ das mulheres em idade ativa estão fora do mercado de trabalho, frente a $6 \%$ dos homens, o que se deve, segundo aponta o relatório, às responsabilidades não remuneradas pela prestação do cuidado.

O exercício do trabalho doméstico não remunerado pelas mulheres aumenta a desigualdade de gênero e repercute diretamente no acesso das meninas à educação, já que muitas são forçadas a abandonar os estudos para se dedicar ao trabalho de cuidado, bem como dificulta o acesso das mulheres aos empregos no mercado formal. Como consequência, passam a ser empregadas em setores econômicos de baixa remuneração e tornam-se desprovidas da proteção da legislação trabalhista e dos sistemas de previdência social.

O relatório da Oxfam Brasil (2020) constatou ainda que meninas e mulheres, sobretudo as que vivem em situação de pobreza e pertencem a grupos marginalizados, dedicam gratuitamente 12,5 bilhões de horas diariamente ao trabalho de cuidado não remunerado, e outras incontáveis horas recebendo uma baixíssima remuneração por essas atividades. Especificamente no Brasil, as mulheres dedicam cerca de 21,3 horas semanais de cuidados domésticos não remunerados, enquanto a média semanal para os homens é de 10,9 horas (MULHERES, 2019). 
Com o ingresso das mulheres no mercado de trabalho, passou a ser exigida a compatibilização das atribuições profissionais com o trabalho de cuidado não remunerado. Conforme defende Louro (1997, p. 96),

\begin{abstract}
Já que se entende que o casamento e a maternidade, tarefas femininas fundamentais, constituem a verdadeira carreira das mulheres, qualquer atividade profissional será considerada como um desvio dessas funções sociais, a menos que possa ser representada de forma a se ajustar a elas (LOURO, 1997, p. 96).
\end{abstract}

Assim, as mulheres passaram a acumular as atribuições profissionais com o planejamento das atividades do lar e execução do trabalho de cuidado doméstico não remunerado. Para as mulheres com maior poder aquisitivo, o trabalho de cuidado foi terceirizado com a contratação de empregados, a maioria mulheres.

Conforme estimativas da Organização Internacional do Trabalho (OIT), (COVID19, 2020) em 12 de junho de 2020, na América Latina e no Caribe, entre 11 e 18 milhões de pessoas dedicam-se ao trabalho doméstico remunerado, sendo $93 \%$ composto por mulheres, e dentro desse percentual, mais de $77,5 \%$ atuam em situação de informalidade, sem acesso à proteção social, a exemplo dos direitos trabalhistas e previdenciários. A renda das mulheres empregadas no serviço doméstico também é igual ou inferior a $50 \%$ da média de todas as pessoas ocupadas.

Em âmbito nacional, as mulheres respondem por 90\% dentre os 6 milhões de trabalhadores domésticos remunerados. Do total, $60 \%$ são mulheres negras e menos de $40 \%$ das profissionais possuem carteira assinada (TRABALHADORAS, 2020). Os dados revelam que, embora tenham sido assegurados direitos trabalhistas às empregadas domésticas que executam o trabalho remunerado, como a EC 72/2013 (BRASIL, 2013) e a Lei Complementar no 150/2015 (BRASIL, 2015), a segregação de raça e gênero ainda se faz presente na execução das atividades, muitas vezes encaradas de forma discriminatória, como resquício dos serviços realizados pelas mulheres negras no período de escravidão.

No contexto do trabalho doméstico remunerado no Brasil, é imprescindível a análise entre as relações de gênero, raça e classe, sob a perspectiva da interseccionalidade. Segundo Crenshaw (2002),

A interseccionalidade é uma conceituação do problema que busca capturar as consequências estruturais e dinâmicas da interação entre dois ou mais eixos da 
subordinação. Ela trata especificamente da forma pela qual o racismo, o patriarcalismo, a opressão de classe e outros sistemas discriminatórios criam desigualdades básicas que estruturam as posições relativas de mulheres, raças, etnias, classes e outras. Além disso, a interseccionalidade trata da forma como ações e políticas específicas geram opressões que fluem ao longo de tais eixos, constituindo aspectos dinâmicos ou ativos do desempoderamento. (CRENSHAW, 2002, p.177).

Ao transferir a execução do trabalho de cuidado para outras mulheres, sobretudo as negras para que as mulheres brancas ingressem no mercado de trabalho, há a perpetuação das relações de escravidão e subordinação de classes. Com isso, conforme afirma Biroli (2018), o trabalho remunerado não é vivenciado da mesma forma pelas mulheres trabalhadoras: enquanto para as mulheres brancas significa autonomia, para as mulheres negras, que ganham, na maior parte das vezes, muito menos do que o salário-mínimo, significa a continuidade da exploração de classe.

Seja sob o viés do trabalho doméstico não remunerado ou remunerado, as mulheres são as mais impactadas pela execução do trabalho de cuidado. A pandemia da COVID-19 inclusive pode acentuar as desigualdades econômicas e de gênero. Conforme estimativas publicadas pelo Departamento Intersindical de Estatística e Estudos Econômicos (DIEESE), uma parcela expressiva de mulheres perdeu a sua ocupação remunerada no período de pandemia e muitas sequer buscaram nova inserção no mercado de trabalho. Entre o terceiro trimestre de 2019 e 2020, o contingente de mulheres fora do mercado de trabalho aumentou 8,6 milhões. E especificamente para as trabalhadoras domésticas remuneradas, 1,6 milhão perdeu os seus empregos, sendo que 400 mil tinham carteira assinada e 1,2 milhão não tinha vínculo formal de trabalho (DIEESE, 2021).

Portanto, urgem criar mecanismos para reduzir as desigualdades de gênero, criar políticas públicas e receitas para proteger as mulheres em situação de vulnerabilidade. Um dos meios apontados é a estruturação de gastos e da tributação para promover a igualdade de gênero.

E sendo certo que a tributação é o principal instrumento do qual o Estado dispõe para financiamento de políticas sociais, prestação de serviços públicos e intervenção na ordem social e econômica, o tema da justiça fiscal foi recuperado por estudiosos que enxergam no sistema tributário um mecanismo de correção das 
disparidades inerentes ao próprio capitalismo. Ademais, as políticas tributárias nem sempre são neutras em relação ao gênero, razão pela qual é necessário analisar como a tributação poderia auxiliar na redução das desigualdades sociais, inclusive com a proteção das mulheres que desempenham trabalhos domésticos.

\section{TRIBUTAÇÃO NO BRASIL: CARACTERÍSTICAS E POTENCIALIDADES}

A Constituição de 1988 (BRASIL, 1988) representou um marco político e normativo importante para a configuração do pacto social que se desejava fundar num contexto de transição para um regime democrático. No campo dos direitos sociais, o texto constitucional abriu caminho para implementação e expansão de políticas públicas voltadas para a inclusão de outsiders ${ }^{2}$, com a consequente redução de desigualdades econômicas até então perpetuadas em virtude de ideais políticos excludentes.

Marta Arretche $(2018$, p. 3) identifica uma efetiva redução da desigualdade econômica durante o regime democrático contemporâneo - que, em sua análise, vai de 1985 a 2015 - em função de uma "mudança paradigmática nos pilares do modelo conservador de política social adotado no país desde Getúlio Vargas". De acordo com a autora,

Por um mecanismo de superposição de vantagens, os insiders acumulavam canais de acesso às políticas do Estado, direitos dos quais estavam excluídos os outsiders. Dispositivos da Constituição Federal (CF) de 1988 erodiram alguns dos pilares dessa histórica divisão entre insiders e outsiders, ao eliminar as regras de titularidade que garantiam benefícios previdenciários e direito à saúde apenas aos inseridos no mercado formal de trabalho (ARRETCHE, 2018, p. 3).

Contudo, é possível afirmar que a progressividade dos gastos, exigida para a efetiva consecução dos objetivos constitucionais de viés equalizador, apenas parcialmente encontra amparo no sistema tributário desenhado pela própria Constituição. Isto porque, o consenso social-liberal que permitiu a criação e expansão de políticas sociais até 2016 (ano do impeachment da presidente Dilma Roussef), se compatibilizava com um mínimo de estabilidade política, social e econômica (ARAÚJO,

\footnotetext{
${ }^{2}$ Marta Arretche (2018, p. 3) entende, por inclusão de outsiders, "a incorporção à titularidade de direitos de aposentadoria, saúde e educação".
} 
2018), bem como com capacidade arrecadatória proporcionada, em certa medida, pelo caráter pró-cíclico da tributação sobre consumo/produção³.

Entretanto, como aponta o Relatório da OXFAM Brasil, intitulado "País estagnado: um retrato das desigualdades brasileiras" (OXFAM BRASIL, 2018), desde 2017 o Brasil vem experimentando retrocessos no projeto de redução das desigualdades sociais, processo que se coaduna com a "adoção de uma fiscalidade austera como reação a um contexto de crise econômica" (SILVA; TAVARES, 2020, p. 2), cujo exemplo emblemático, em termos de produção legislativa, é a Emenda Constitucional no 95/2016 (BRASIL, 2016). Apenas exemplificativamente, importa destacar que, segundo dados das PNAD contínuas, as mulheres ganhavam cerca de $72 \%$ do que ganhavam os homens em 2016 , proporção que caiu para $70 \%$ em 2017 , o que representou o primeiro recuo em 23 anos (OXFAM BRASIL, 2018, p. 22). Em linhas gerais, segundo o estudo,

Tal cenário é a marca de uma crise econômica, fiscal e política que vivemos desde fins de 2014. Houve retração geral da renda nacional desde então, produto da recessão que praticamente fez dobrar o desemprego no país, de $6,8 \%$ em 2014 para $12,7 \%$ em 2017. Tal movimento afetou muito mais os pobres, as mulheres e a população negra (OXFAM BRASIL, 2018, p. 11).

Assim, é de extrema importância analisar as características da tributação no Brasil como forma de identificar relações de causa e efeito entre a exploração de bases econômicas tributáveis e a perpetuação ou superação de desigualdades econômicas e sociais. Se é possível concluir que a Constituição de 1988 é paradoxal por relegar à legislação infraconstitucional aspectos essenciais para efetiva tributação da renda e do patrimônio, como contrapartida financeira para a expansão do Estado de bem-estar social proposto (FANDIÑO; KERSTENETZKY, 2019), é igualmente possível concluir que existem potencialidades nas bases econômicas eleitas pelo texto constitucional como riquezas tributáveis, a fim de garantir um sistema tributário de caráter redistributivo.

A primeira característica da tributação no Brasil, digna de nota, é a ênfase dada à denominada tributação indireta, que incide sobre bens e consumo (da qual a tributação através do ICMS, IPI, PIS e COFINS são exemplos). De acordo com dados

\footnotetext{
${ }^{3}$ Diz-se que a tributação sobre produção/consumo tem caráter pró-cíclico na medida em que a arrecadação dela proveniente guarda estreita relação com a estabilidade dos ciclos econômicos.
} 
da OCDE para $2015^{4}$, numa composição da carga tributária segregada por bases de incidência, enquanto a tributação da renda e do patrimônio no Brasil representa 22,7\% do PIB, a tributação do consumo representa 49,7\%, enquanto a média da OCDE é de $39,6 \%$ e $32,4 \%$, respectivamente.

Ao passo que a tributação direta se vale, em tese, da identificação de signos presuntivos de riqueza para escalonamento dos contribuintes de acordo com a quantidade de renda e de patrimônio, a fim de distribuir de maneira justa e igualitária o ônus da tributação, a tributação indireta acaba por repassar indiscriminadamente esse ônus para todos os contribuintes, através de mecanismos que embutem os custos tributários da cadeia de produção no preço final dos produtos consumidos.

É por esse motivo que a tributação indireta é considerada regressiva para os grupos sociais de baixa renda: entre composições familiares dos $20 \%$ mais ricos, a tributação indireta tem participação de $11 \%$ a $13 \%$ na renda familiar, enquanto entre composições familiares dos $40 \%$ mais pobres, a tributação indireta tem participação de $14 \%$ a $18 \%$ na renda familiar ${ }^{5}$. Conclui-se, então, que os impostos indiretos são "reconhecidamente regressivos porque sua incidência não tem como referência a renda do consumidor, mas apenas o seu consumo, não diferenciando, portanto, seus diferentes níveis de poder aquisitivo" (OLIVEIRA, 2020, p. 282).

É importante destacar que, no Brasil, a carga tributária em relação ao PIB nacional é de 33\% (dados para 2015), o que, num primeiro momento, indica uma elevada carga tributária quando comparada a outras economias. Contudo, como aponta Fabrício Augusto de Oliveira (2020),

o maior problema da carga tributária no Brasil reside não tanto na sua dimensão, que, pelos motivos apontados, não deixa de ter efeitos nocivos para a competitividade da produção nacional e para a oferta de políticas sociais, mas principalmente na sua composição (OLIVEIRA, 2020, p. 281).

Logo, para além de um sistema tributário apoiado em grande medida numa carga tributária sensível aos ciclos econômicos, pode-se dizer que a ênfase dada à tributação indireta, num país de históricas desigualdades econômicas e sociais, apenas

\footnotetext{
${ }^{4}$ Dados extraídos da tabela que compõe o Documento intitulado Tributar os Super-Ricos para reconstruir o país, publicado em julho/2020 e disponível para acesso na Plataforma Política Social.

5 Dados extraídos do Relatório da Oxfam Brasil (2018) intitulado País Estagnado: um retrato das desigualdades brasileiras.
} 
reproduz conjunturas incompatíveis com os ideais de justiça fiscal, preconizados pela Constituição de 1988 (BRASIL, 1988).

No que diz respeito à tributação da renda, o sistema tributário nacional se desenvolveu timidamente, em que pese a previsão constitucional acerca da progressividade que deve informar a instituição do imposto de renda (art. 153, §2 inciso I da CRFB), bem como a necessidade de observância, sempre que possível, do princípio da capacidade contributiva e da pessoalidade, quando da instituição dos impostos (art. 145, $\S 1^{\circ}$ da CRFB). Tais princípios são considerados fundamentais para a efetiva implementação de justiça fiscal, tanto em termos redistributivos, quanto distributivos. De acordo com Ricardo Lodi Ribeiro (2019),

A tributação tem um relevante papel no combate às desigualdades sociais, não só pela redistribuição de renda, através da possibilidade de financiar a introdução de prestações positivas aos mais pobres, a partir de recursos orçamentários obtidos por meio da taxação dos mais ricos, mas ainda pela distribuição de rendas, que não tem propriamente o conteúdo redistributivo, mas baseia-se apenas nas receitas e na ideia de uma divisão justa do ônus fiscal pela capacidade contributiva, por meio da progressividade e da tributação sobre as grandes riquezas, a fim de evitar a concentração de renda (RIBEIRO, 2019, p. 168-169).

É interessante notar que um dos principais paradoxos da tributação da renda no Brasil está relacionado à reforma na legislação do Imposto de Renda levada a efeito em 1995, pela Lei no 9.249 (BRASIL, 1995), que instituiu a isenção do imposto para lucros e dividendos de sócios e acionistas e permitiu a dedução, do lucro tributável da pessoa jurídica, dos juros sobre capital próprio pagos aos sócios e acionistas ${ }^{6}$. Disso resulta que "uma parcela do lucro, que seria tributada pelo IRPJ e pela contribuição social sobre o lucro líquido (CSLL) à alíquota de 34\%, passa a ser tributada a apenas 15\%, quando paga ao acionista", enquanto "os dividendos, antes tributados a $15 \%$ como os demais ganhos de capital, passariam a ser isentos" (GOBETTI; ORAIR, 2016, p. 12).

\footnotetext{
${ }^{6}$ Art. 9 A pessoa jurídica poderá deduzir, para efeitos da apuração do lucro real, os juros pagos ou creditados individualizadamente a titular, sócios ou acionistas, a título de remuneração do capital próprio, calculados sobre as contas do patrimônio líquido e limitados à variação, pro rata dia, da Taxa de Juros de Longo Prazo - TJLP. Art. 10. Os lucros ou dividendos calculados com base nos resultados apurados a partir do mês de janeiro de 1996, pagos ou creditados pelas pessoas jurídicas tributadas com base no lucro real, presumido ou arbitrado, não ficarão sujeitos à incidência do imposto de renda na fonte, nem integrarão a base de cálculo do imposto de renda do beneficiário, pessoa física ou jurídica, domiciliado no País ou no exterior.
} 
Some-se a isso o fato de que a progressividade da alíquota do Imposto de Renda da Pessoa Física leva em consideração apenas cinco faixas de rendimentos, sendo a alíquota máxima de $27,5 \%$. O que se observa é uma tributação mais favorecida aos rendimentos do capital em contraposição à tributação dos rendimentos do trabalho.

\section{O SISTEMA TRIBUTÁRIO E A REALIDADE ECONÔMICA DAS MULHERES}

Muito se discute sobre Justiça Fiscal no viés da tributação como meio de redução das desigualdades entre ricos e pobres. Entretanto, também é necessário analisar como a política tributária pode ser concebida para favorecer ou dificultar a efetivação dos direitos fundamentais, e os mecanismos pelos quais a legislação tributária pode eventualmente evidenciar discriminações presentes na sociedade, a exemplo de gênero, raça e orientação sexual.

Embora a tributação não seja a principal responsável por criar desigualdades sociais dos grupos historicamente excluídos do debate tradicional, a conjuntura histórica e sociológica da ausência de políticas públicas voltadas a tentar corrigir as distorções pode reflexamente impactar em uma maior tributação de grupos específicos, em violação ao princípio da capacidade contributiva.

Chiara Capraro (2016) ressalta que as mulheres possuem uma presença substancial entre as pessoas de baixa renda, e há estudos que demonstram serem afetadas pelos impostos de maneiras específicas devido aos seus padrões de emprego, incluindo salários, a participação no trabalho de cuidado não remunerado, os padrões de consumo e sua posse de bens e propriedades.

Mesmo inseridas no mercado de trabalho e com maior escolaridade do que os homens, as mulheres ainda recebem remunerações menores. Conforme pesquisa do IBGE, em 2018, o salário médio das mulheres correspondia a $79,5 \%$ ao dos homens. $E$ quanto ao grau de instrução, em 2016, as mulheres que exerciam atividade remunerada e ensino superior completo representavam $16,9 \%$ da força produtiva no mercado de trabalho, enquanto apenas $13,5 \%$ dos homens possuíam o mesmo nível de instrução (VILLAS BÔAS, 2019a). Some-se a todo o exposto o fato de que existem mais de 32,2 milhões de mulheres chefes de família no país, com a responsabilidade de serem a 
única fonte de renda da entidade familiar (VILLAS BÔAS, 2019b).

Conforme já frisado, a tributação indireta sobre bens e serviços é apontada como um dos mecanismos que mais contribuem para as desigualdades patrimoniais. Nessa sistemática, as mulheres são ainda mais prejudicadas, pois se observa que produtos direcionados ao público feminino possuem um preço maior em relação ao masculino, fato que deu ensejo aos estudos sobre "pink tax" ou "gender bias". Em artigo sobre o tema, Torres (2020) explica que o termo se refere às diferenças dos preços e dos tributos de produtos destinados a mulheres, geralmente mais caros, realidade mesmo em países como Inglaterra, Estados Unidos e França. Nos Estados Unidos, por exemplo, foi apurada a existência de diferenciação no preço do seguro-saúde, que era mais elevado para mulheres (Affordable Care Act).

Nos Estados Unidos, foi realizado um estudo sobre preços de gênero pelo departamento de assuntos do consumidor (DCA) de Nova York, e constatou-se que os produtos femininos custam mais do que os masculinos em $42 \%$ dos casos (YAZICIOGLU, 2018; PETROU, 2017; DE BLASIO; MENIN, 2015). Embora o pink tax se trate de um fenômeno mercadológico e não tributário, na medida em que os produtos direcionados ao público feminino são mais caros do que os do público masculino, as mulheres pagam mais tributos sobre o consumo, já que o preço do produto impacta o valor dos tributos incidentes, situação que demonstra uma possível violação ao princípio da essencialidade, ao implicar um impacto financeiro maior para as mulheres na tributação incidente sobre o consumo, não bastasse o fato de possuírem renda inferior aos homens.

Outrossim, observou-se que produtos tipicamente femininos ou relacionados ao cuidado, a exemplo de absorventes, fraldas e bombas de amamentação, são tributados com alíquotas elevadas, como itens supérfluos. Observe-se o caso dos absorventes, produto destinado à contenção do fluxo menstrual e, portanto, de uso exclusivo de meninas e mulheres cisgênero, homens trans e pessoas não binárias, por uma necessidade biológica. Enquanto em alguns países os absorventes possuem alíquota zero ou reduzida nos tributos incidentes, a exemplo de Alemanha, França, Portugal, Quênia, Colômbia e Nigéria, no Brasil, apesar de atualmente sujeitos à alíquota zero do 
IPI, os absorventes higiênicos sujeitam-se a uma tributação, em média, de $25 \%$ sobre o valor do item.

Tathiane Piscitelli et al. (2020) alerta ainda para outras situações em que há uma maior tributação para bens de consumo adquiridos majoritariamente pelas mulheres no Brasil, a exemplo da tributação das bombas de amamentação (18\% ICMS e $5 \%$ de IPI), adaptadores de silicone para seios durante a amamentação (18\% de ICMS e $10 \%$ de IPI) e fraldas descartáveis (18\% de ICMS e $15 \%$ de IPI), itens que evidenciam como as mulheres são ainda mais oneradas na tributação sobre o consumo e demonstram a necessidade de repensar o atual modelo brasileiro de tributação.

A tributação da renda é apresentada como mecanismo mais eficaz para a obtenção da justiça fiscal, na medida em que a progressividade seria um mecanismo para a redistribuição da riqueza. Teoricamente, contribuintes que realizam o fato gerador e se enquadram na mesma faixa de rendimentos devem pagar o mesmo valor do tributo. Entretanto, no Brasil, a baixa progressividade das alíquotas acentua as desigualdades econômicas.

A legislação do imposto de renda no Brasil para as pessoas físicas teoricamente reconhece exclusões, deduções e isenções de determinadas despesas na apuração da base de cálculo da renda tributável independente do gênero. Todavia, mesmo inseridas no mercado de trabalho e com maior escolaridade do que os homens, as mulheres ainda recebem remunerações menor ${ }^{7}$. Ademais, enquanto os rendimentos tributáveis das mulheres em média correspondem a $65 \%$ dos seus rendimentos totais, para os homens essa relação é de $57 \%$. Com isso, as mulheres não apenas recebem rendimentos inferiores aos dos homens, como também são prejudicadas ao receber maiores rendimentos tributáveis do que estes (AFONSO; LUKIC; ORAIR, 2017, p. 123).

Para tentar entender a problemática exposta, necessário mencionar aos estudos de Janet Gale Stotsky (1997) sobre as desigualdades de gênero e os sistemas tributários dos países em desenvolvimento. Para a autora, a análise do viés de gênero da tributação deve observar tanto a forma explícita quanto a implícita de discriminação. O viés explícito geralmente se apresenta como um tratamento diferenciado entre

\footnotetext{
${ }^{7} \mathrm{Em} \mathrm{2016}$, as mulheres que exerciam atividade remunerada e ensino superior completo representavam $16,9 \%$ da força produtiva no mercado de trabalho, enquanto apenas $13,5 \%$ dos homens possuíam o mesmo nível de instrução (VILLAS BÔAS, 2019a).
} 
homens e mulheres, presente na própria legislação; já o viés implícito, mais difícil de ser percebido, são as implicações das leis em determinado contexto social e econômico que impactarão homens e mulheres de forma diferente.

Uma vez que as mulheres possuem rendimentos menores e ocupam proporcionalmente aos homens poucas posições de chefia e gestão no mercado de trabalho ${ }^{8}$, consequentemente pagarão mais imposto de renda. Muito embora a tributação explicitamente não faça distinção de gênero, a distorção existe na medida em que as mulheres recebem salários menores, pagam os mesmos tributos indiretos e muitas são responsáveis pela única fonte de renda dos seus lares. Nesse contexto, a igualdade, em sua perspectiva material, prevista na legislação, afasta-se dos objetivos Constitucionais, razão pela qual é necessária a consecução de uma política tributária que diminua as assimetrias de renda e especificamente de gênero.

\section{POSSÍVEIS CAMINHOS PARA REDUÇÃO DAS DESIGUALDADES, INCLUSIVE DE GÊNERO, ATRAVÉS DA TRIBUTAÇÃO}

Como apontado linhas atrás, há cinco anos o país experimenta os efeitos de uma crise econômica, política e social que tem impactado principalmente os mais vulneráveis. Desde 2020, a pandemia do novo coronavírus evidencia desigualdades já existentes, demonstrando a urgência na adoção de medidas que minimizem as consequências sociais dessa crise sanitária. Discursos sobre um novo contrato social pós-pandemia ${ }^{9}$ emergem no debate público, apontando para a necessidade de reflexões sobre uma nova ordem econômica, bem como sobre o papel do Estado no enfrentamento dessa crise.

As consequências da pandemia do novo coronavírus para o mercado de trabalho brasileiro são expressivas. De acordo com dados compilados no estudo Tributar os super-ricos para reconstruir o país (MOREIRA FILHO et al., 2020), a crise atual é comparada às mais graves crises do capitalismo no século XX. No Brasil, até

\footnotetext{
${ }^{8}$ A Lei no 9.249/95 previu a isenção de lucros e dividendos distribuídos pela pessoa jurídica. Os cargos de gestão são majoritariamente ocupados por homens, situação que pode explicar as diferenças na tributação sobre a renda entre homens e mulheres (BRASIL, 1995).

${ }_{9}$ Sobre a necessidade de uma atuação conjunta da iniciativa privada e do poder público para superação dos efeitos da crise, consultar o artigo "O contrato social pós-pandemia" (RODRIK; STANTCHEVA, 2020). 
meados de 2020, existiam mais pessoas fora do mercado de trabalho do que trabalhando - 87,7 milhões e 85,9 milhões, respectivamente. Houve uma perda de 2,5 milhões de postos de trabalho para empregados com carteira no setor privado (queda de 7,5\%), e de 2,4 milhões de postos de trabalho sem carteira no setor privado (queda de 20,8\%). Quanto aos trabalhadores autônomos, a queda experimentada foi de $8,4 \%$, o que representa 2,1 milhões de pessoas, enquanto o número de trabalhadores domésticos declinou $18,9 \%$, isto é 1,2 milhão a menos.

No que diz respeito aos efeitos da pandemia sobre as mulheres e sua situação econômica, estudos ${ }^{10}$ indicam um cenário de desproporcionalidade: i) pela maior probabilidade de as mulheres trabalharem em setores sociais, que exigem interação direta, a exemplo do trabalho doméstico remunerado, e, por esse motivo, mais atingidos pelas medidas de mitigação e distanciamento social - no Brasil, $6,7 \%$ das mulheres empregadas em setores sociais não conseguem trabalhar remotamente; ii) pelo fato de que mais mulheres tendem a trabalhar no setor informal nos países de baixa renda, o que tem afetado profundamente o seu sustento, em virtude da crise provocada pela COVID-19; iii) em grande medida, pelo fato de que as mulheres tendem a assumir mais tarefas domésticas não remuneradas que os homens, além de arcar com o ônus das responsabilidades de cuidado familiar, decorrentes das medidas de paralisação.

O recente Relatório da OXFAM intitulado The inequality virus (BERKHOUT et al., 2021) indica que, no mundo, 112 milhões de mulheres não teriam o risco de perder suas rendas e empregos se homens e mulheres estivessem representados de forma igualitária em setores negativamente atingidos pela crise da COVID-19.

O mesmo Relatório apresenta dados importantes sobre a concentração de renda entre os mais ricos, especificamente entre os bilionários. Ao passo que os 1000 maiores bilionários do mundo levaram apenas nove meses para suas fortunas retornarem aos níveis anteriores à pandemia, a recuperação dos mais pobres do mundo pode levar mais de uma década. Entre 18 de março e 31 de dezembro de 2020, a riqueza dos bilionários em todo mundo aumentou em US\$3,9 trilhões, e sua riqueza total é de US\$11,95 trilhões, o que seria o equivalente ao que os governos do G20

\footnotetext{
10 Para detalhes do estudo, consultar o artigo "A COVID-19 e as diferenças de gênero" (GEORGIEVA,
} 2020). 
gastaram em resposta à pandemia. Quanto ao total de pessoas que vivem na pobreza, estima-se que pode ter aumentado entre 200 milhões e 500 milhões, e que esse número pode não voltar ao nível anterior à crise por mais de uma década.

Assim, a necessidade de se pensar uma nova economia é patente, uma vez que a concentração de renda e o acirramento das desigualdades dela proveniente, produtos de um capitalismo de viés neoliberal, são prejudiciais para o crescimento econômico e, principalmente, para a construção de uma rede de proteção social democrática. Como aponta Ladislau Dowbor (2020),

O que produzimos no mundo permite assegurar, com moderada redução da desigualdade, vida digna e confortável para todos. O equivalente para o Brasil, com um PIB de 7,3 trilhões de reais e uma população de 212 milhões, seria de 11 mil reais. Nosso desafio não é produzir mais, mas distribuir de maneira equilibrada. Entre março e julho de 2020, em plena pandemia, em 4 meses, 42 bilionários (em dólares) brasileiros aumentaram as suas fortunas em 180 bilhões de reais, o equivalente a 6 anos de Bolsa Família. São isentos de impostos. A economia se tornou sistematicamente disfuncional: é a legalidade divorciada do que é legítimo (DOWBOR, 2020, p. 12).

Importa destacar que a tributação está no cerne das discussões sobre possíveis caminhos para recuperação econômica durante a pandemia do novo coronavírus. $\mathrm{O}$ Fundo Monetário Internacional (FMI) tem sinalizado aos governos a necessidade de considerar a implementação de impostos sobre a riqueza para aumentar a receita, enquanto a pandemia atinge as economias, numa completa reviravolta nas diretrizes políticas e econômicas da própria instituição ${ }^{11}$. O Secretário-Geral das Nações Unidas, Antônio Guterres, em julho de 2020, ao apontar os desafios para o combate às desigualdades aprofundadas pela crise, reforçou a necessidade dos governos adotarem "uma tributação justa sobre a renda e a riqueza, e uma nova geração de políticas de proteção social, com redes de segurança incluindo a Cobertura Universal de Saúde e a possibilidade de uma Renda Básica Universal estendida a todos". ${ }^{12}$

Em dezembro de 2020, os meios de comunicação noticiaram a aprovação, na Argentina, da lei regulamentadora do Imposto sobre Grandes Fortunas, que objetiva fazer frente aos gastos necessários para sanear a crise econômica enfrentada pelo país,

\footnotetext{
11 Para maiores informações, consultar o artigo "The IMF says governments should consider new wealth taxes to raise cash from the rich as coronavirus slams the global economy" (ZEBALLOS-ROIG, 2020).

12 Para acesso ao pronunciamento completo, consultar (GUTERRES, 2020).
} 
e agravada pela pandemia da Covid-19. Segundo dados divulgados pelo El País ${ }^{13}$, a lei denominada Aporte Solidário e Extraordinário alcançará cerca de 12 mil pessoas, das quais 380 estão no topo da escala de contribuição, com ativos declarados de mais de 35 milhões de dólares. A taxação das grandes fortunas, que poderá variar de $2 \%$ a 3,5\%, será responsável pela arrecadação de cerca de 3,5 bilhões de dólares, conforme estimativa do Poder Executivo.

No Brasil, a pauta atual e hegemônica acerca da tributação, que vem ocupando os espaços de deliberação política, gira em torno de duas principais propostas de reforma tributária em trâmite no Congresso Nacional. Com o objetivo de imprimir maior dinamismo e simplificar a tributação sobre produção e consumo, as propostas de Emenda Constitucional no 45 e 110 de 2019 (em trâmite na Câmara dos Deputados e no Senado Federal, respectivamente) sugerem a criação de um imposto único, denominado Imposto sobre Bens e Serviços (IBS), à semelhança de um Imposto sobre Valor Agregado (IVA) adotado em outros países.

A tabela 1 abaixo sintetiza as principais modificações propostas pelo Congresso Nacional, no que diz respeito às competências tributárias previstas atualmente no texto constitucional.

Tabela 1 - Principais modificações propostas pelo Congresso Nacional.

\begin{tabular}{|c|c|c|}
\hline & Proposta da Câmara & Proposta do Senado \\
\hline $\begin{array}{l}\text { Impostos sobre bens e } \\
\text { serviços }\end{array}$ & $\begin{array}{l}\text { Substituição de cinc } \\
\text { tributos (PIS, Cofins e IP } \\
\text { federais, ICMS estadual } \\
\text { ISS municipal) por dois: IBS } \\
\text { nacional e IS federal. }\end{array}$ & $\begin{array}{l}\text { Substituição de nove tributos } \\
\text { I(PIS, Cofins, IPI, Cide- } \\
\text { combustíveis, IOF, Pasep e } \\
\text { salário-educação federais, } \\
\text { ICMS estadual e ISS } \\
\text { municipal) por dois: IBS } \\
\text { estadual e IS federal. }\end{array}$ \\
\hline Impostos sobre renda & - & $\begin{array}{l}\text { Extinção da Contribuição } \\
\text { Social sobre o Lucro Líquido } \\
\text { (CSLL), incorporada ao } \\
\text { Imposto de Renda de } \\
\text { Pessoa Jurídica (IRPJ), com } \\
\text { gradual desvinculação da }\end{array}$ \\
\hline
\end{tabular}

\footnotetext{
${ }^{13} \mathrm{~A}$ matéria intitulada "Argentina aprova imposto sobre grandes fortunas para financiar a luta contra o coronavírus" foi divulgada em 06 dez. 2020 (MOLINA, 2020).
} 


\begin{tabular}{|c|c|c|}
\hline & & $\begin{array}{l}\text { seguridade social. } \\
\text { Ampliação da base de } \\
\text { incidência do IRPF para } \\
\text { incluir verbas indenizatórias. }\end{array}$ \\
\hline Tributos sobre folha salarial & - & $\begin{array}{l}\text { Fim do salário-educação, } \\
\text { incorporado ao IBS estadual. }\end{array}$ \\
\hline Impostos sobre propriedade & - & $\begin{array}{l}\text { Transferência } \\
\text { competência para tributar } \\
\text { heranças e doações } \\
\text { (Imposto sobre Transmissão } \\
\text { Causa Mortis e Doação - } \\
\text { ITCD) da esfera estadual } \\
\text { para a federal. } \\
\text { Ampliação da base de } \\
\text { incidência do Imposto sobre } \\
\text { a Propriedade de Veículos } \\
\text { Automotores (IPVA) para } \\
\text { abarcar, além de veículos } \\
\text { automotores terrestres, } \\
\text { veículos aquáticos e aéreos } \\
\text { (exclusive veículos de uso } \\
\text { comercial na pesca ou no } \\
\text { transporte público de } \\
\text { passageiros e cargas). } \\
\text { Gradual redirecionamento da } \\
\text { totalidade das receitas do } \\
\text { ITCD e do IPVA para os } \\
\text { municípios. }\end{array}$ \\
\hline
\end{tabular}

Fonte: Tabela extraída do estudo publicado pelo Instituto de Pesquisa Econômica (IPEA), em 2019 (GOBETTI; ORAIR, 2019), intitulado "Reforma Tributária e Federalismo Fiscal: uma análise das propostas de criação de um novo imposto sobre o valor adicionado para o Brasil".

É interessante notar que as propostas de reforma tributária em pauta objetivam a modificação do texto constitucional, para alteração de competências tributárias, sem, contudo, se ocuparem da reformulação da tributação da renda e do patrimônio, em âmbito infraconstitucional, e sem se preocupar com a redução das desigualdades sociais. Repensar a tributação sobre a produção e o consumo é necessário, tendo em vista o seu impacto sobre o crescimento econômico, a competitividade da produção interna em âmbito internacional e a atratividade do país para investimentos.

Contudo, a crise enfrentada pelo país, agravada de maneira substancial pela pandemia da COVID-19, tornou tais propostas anacrônicas, na medida em que estão 
divorciadas de um compromisso com um verdadeiro estado de bem-estar social, que promova inclusão social e redução das desigualdades, inclusive de gênero. Como aponta o estudo Tributar os super-ricos para o crescimento do país (MOREIRA FILHO et al., 2020),

A agenda hegemônica da Reforma Tributária que tramita no Congresso Nacional está desconectada dessa realidade. Antes da Covid-19 essa agenda já era injusta e limitada, porque as duas propostas hegemônicas em tramitação não enfrentam a principal anomalia da tributação brasileira que é o seu caráter regressivo, não reduzem e podem ampliar a desigualdade, e são profundamente insuficientes, porque não fortalecem financeiramente o Estado para que cumpra o papel dele exigido em crises dessa envergadura. Ambas as propostas são omissas quanto à tributação da alta renda e da riqueza e contemplam, exclusivamente, a tributação do consumo. A esperada agenda da Reforma Tributária transformou-se na agenda da Reforma da Tributação do Consumo (MOREIRA FILHO et al., 2020, p. 30).

O referido estudo propõe algumas medidas tributárias - emergenciais e permanentes - para enfrentar a crise agravada pela pandemia da COVID-19 (primordialmente através de alterações legislativas em âmbito infraconstitucional).

Dentre as medidas permanentes e estruturantes propostas pelo estudo, podese destacar a revogação dos artigos 9 e 10 da Lei no 9.249/1995 (isenção de lucros e dividendos e dedução dos juros sobre capital próprio) (BRASIL, 1995), bem como a instituição de uma nova tabela progressiva para o Imposto de Renda Pessoa Física, com aumento da faixa de isenção para as camadas de baixa renda (de $R \$ 1.908,00$ para $\mathrm{R} \$ 2.862,00$, o que beneficiaria 10,1 milhões de pessoas), ampliação das faixas de alíquota, de 4 para 7 faixas, bem como com a elevação da alíquota máxima incidente sobre as faixas de renda mais elevadas (elevação de $27,5 \%$ para $45 \%$ ). Importa ressaltar que o referido estudo teve como ponto de partida o Manifesto "Tributar os ricos para enfrentar a crise", produzido, conjuntamente, pela Associação Nacional dos Auditores Fiscais da Receita Federal (ANFIP), Auditores Fiscais pela Democracia (AFD), Federação Nacional do Fisco Estadual e Distrital (FENAFISCO) e Instituto Justiça Fiscal (IJF).

Estima-se que essas alterações representariam um acréscimo de $74 \%$ do total do imposto atualmente arrecadado e, com base em dados de 2018, a base de incidência do IRPF se elevaria de $R \$ 1,8$ trilhão para $R \$ 2,4$ trilhões, pela inclusão, na tabela progressiva proposta, dos rendimentos atualmente isentos ou dedutíveis. $O$ 
estudo identifica um ganho arrecadatório potencial da ordem de $\mathrm{R} \$ 165$ bilhões. Assim, enquanto a desoneração estimada, em faixas de renda mais baixas, resultaria na perda arrecadatória de $\mathrm{R} \$ 15,6$ milhões, o aumento de arrecadação para os altos rendimentos geraria uma diferença liquida de $\mathrm{R} \$ 7,8$ bilhões.

No que diz respeito ao Imposto sobre Grandes Fortunas (IGF), que carece de regulamentação desde a promulgação da Constituição de 1988 (BRASIL, 1988), o estudo propõe a sua incidência sobre o conjunto de bens de qualquer natureza de valor superior a $R \$ 10$ milhões, o que alcançaria apenas 60 mil pessoas que, segundo dados da Receita Federal do Brasil, possuem patrimônio declarado superior a esse montante. A progressividade das alíquotas se daria sobre faixas patrimoniais que variam de $R \$ 10$ milhões a $R \$ 80$ milhões $(0,5 \%$ : $R \$ 10$ milhões a 40 milhões; $1 \%$ : acima de $R \$ 40$ milhões até $R \$ 80$ milhões; $1,5 \%$ acima de $R \$ 80$ milhões).

O estudo também propõe a criação da Contribuição Social sobre Altas Rendas da Pessoa Física, que passaria a integrar as fontes de financiamento da Seguridade Social para incremento de políticas sociais, que incidiria a uma alíquota de $10 \%$ apenas sobre os rendimentos totais que excederem ao valor anual de $\mathrm{R} \$ 720$ mil, e afetaria um universo estimado de 208 mil pessoas, que representam apenas $0,09 \%$ da população brasileira.

Com a implementação dessas e das demais medidas propostas, o estudo estima um incremento anual de $R \$ 291,8$ trilhões na receita tributária, na seguinte proporção: i) $R \$ 158$ bilhões, com o tratamento isonômico na tributação da renda e a maior progressividade do IRPF; ii) $\mathrm{R} \$ 40$ bilhões, com a regulamentação do Imposto sobre Grandes Fortunas (IGF); iii) $\mathrm{R} \$ 40,5$ bilhões, com a majoração da alíquota da Contribuição Social com o Lucro Líquido; iv) 35 bilhões, com a criação da Contribuição Social sobre Altas Rendas; v) $\mathrm{R} \$ 14$ bilhões, com a proposta de alteração do Imposto sobre Transmissão Causa Mortis e Doações (ITCMD); vi) R\$ 5 bilhões, com a revogação da dedução dos juros sobre capital próprio (JCP), decorrente apenas do seu pagamento às pessoas físicas residentes no país; vii) uma redução de $R \$ 653$ milhões, decorrente da proposta de isenção das parcelas de Imposto de Renda Pessoa Jurídica (IRPJ) e CSLL dos optantes do SIMPLES, com receita bruta total inferior a $\mathrm{R} \$ 300$ mil por ano. 
O potencial arrecadatório das medidas propostas sinaliza a necessidade e a viabilidade da reavaliação da tributação da renda e do patrimônio no Brasil, uma vez que a própria Constituição de 1988 impõe, como um dos objetivos fundamentais da República Federativa, a construção de uma sociedade livre, justa e solidária, bem como a erradicação da pobreza e da marginalização e a redução das desigualdades sociais e regionais (art. $3^{\circ}$, incisos 1 e III). Sendo a tributação uma das principais fontes de receita de que dispõe o Estado para prestação de serviços públicos e construção de redes de proteção social, políticas de inclusão econômica e social das mulheres que desempenham trabalho em âmbito doméstico, em suas variadas formas, devem ser pensadas a partir da exploração justa das bases econômicas tributáveis. Retomando as lições de Ricardo Lodi Ribeiro (2019),

De todo modo, a tributação é uma intervenção mais indireta na vida econômica dos indivíduos e, por meio dos impostos sobre a renda, herança, patrimônio e, em alguma medida, consumo de luxo, pode se traduzir em importante mecanismo de combate à desigualdade. Se os recursos arrecadados com a tributação progressiva são utilizados em despesas de educação, saúde e assistência social, há um ataque frontal à desigualdade, aliado ao pagamento de subsídios às pessoas mais pobres, por meio de mecanismos como 0 imposto de renda negativo (RIBEIRO, 2019, p. 174).

Necessário destacar adicionalmente aos estudos já relatados, a existência de uma proposta de reforma tributária realizada pelo grupo de pesquisas Tributação $e$ Gênero, do Núcleo de Direito Tributário da Escola de Direito de São Paulo da Fundação Getúlio Vargas, em parceria com o Movimento Tributos a Elas, composto por Procuradoras da Fazenda Nacional, pesquisadoras e advogadas privadas, com propostas de reforma tributária com enfoque no viés de gênero ${ }^{14}$.

A tabela 2 abaixo sintetiza as principais propostas do estudo, no que diz respeito à mitigação das desigualdades de gênero:

Tabela 2 - Principais propostas do estudo à mitigação das desigualdades de gênero.

\begin{tabular}{|l|l|}
\hline & Proposta do grupo de pesquisas Tributação e Gênero \\
\hline Tributação sobre o consumo & $\begin{array}{l}\text { 1. Concessão de isenção de PIS/COFINS e IPI sobre } \\
\text { absorventes íntimo femininos e assemelhados }\end{array}$ \\
\hline
\end{tabular}

${ }^{14}$ FGV Direito São Paulo. Reforma tributária e desigualdade de gênero (PISCITELLI et al., 2020). 


\begin{tabular}{|c|c|c|}
\hline & $\begin{array}{l}2 . \\
3 . \\
4 .\end{array}$ & $\begin{array}{l}\text { (calcinhas absorventes e coletores menstruais) e } \\
\text { fraldas higiênicas infantil e adulta, além da inclusão, } \\
\text { no Anexo I - Produtos integrantes da cesta básica, } \\
\text { do PL 3887/2020; } \\
\text { Concessão de isenção de PIS/COFINS e IPI sobre } \\
\text { anticoncepcionais, além da inclusão, no Anexo I - } \\
\text { Produtos integrantes da cesta básica, do PL } \\
3887 / 2020 \text {; } \\
\text { Manutenção da desoneração dos itens da cesta } \\
\text { básica na proposta da PEC } 45 / 2020 \text {; } \\
\text { Assegurar a isenção de PIS/COFINS e IPI sobre } \\
\text { medicamentos utilizados em reposição hormonal } \\
\text { por conta da menopausa, e na redesignação } \\
\text { sexual, além da previsão de isenção no PL } \\
3887 / 2020 \text {, que cria a CBS, contribuição sobre e } \\
\text { serviços, de competência da União. }\end{array}$ \\
\hline Tributação da Renda & $\begin{array}{l}1 . \\
2 . \\
\\
3 . \\
4 . \\
4 \\
5 .\end{array}$ & $\begin{array}{l}\text { Retorno da dedução do IRPF dos valores } \\
\text { referentes à contribuição previdenciária paga aos } \\
\text { trabalhadores e trabalhadoras domésticas, como } \\
\text { forma de estimular a formalização desses postos de } \\
\text { trabalho, ao lado da criação de um benefício direto } \\
\text { à categoria; } \\
\text { Dedução do IRPF dos valores referentes a gastos } \\
\text { com educação dos trabalhadores e trabalhadoras } \\
\text { domésticas e seus descendentes diretos pagos } \\
\text { pelos empregadores; } \\
\text { Dedução da pensão alimentícia na declaração de } \\
\text { ajuste anual do responsável não alimentante; } \\
\text { Dedução do imposto de renda das pessoas } \\
\text { jurídicas para empresas que contratem mulheres } \\
\text { chefes de família e/ou mulheres negras e que } \\
\text { tenham políticas de inclusão de mulheres em } \\
\text { cargos de gestão; } \\
\text { Criação de programas nacionais específicos com o } \\
\text { objetivo de apoiar o desenvolvimento de projetos de } \\
\text { afroempreendedorismo feminino, incluindo linha de } \\
\text { crédito diferenciada, com subsídios } \\
\text { governamentais, desoneração da carga tributária e } \\
\text { o oferecimento de cursos de planejamento e gestão } \\
\text { direcionados para o afroempreendedorismo; }\end{array}$ \\
\hline
\end{tabular}

Fonte: Autora (2021). 
A proposta de reforma tributária com viés de gênero demonstra que existem alternativas na política tributária para incluir as mulheres no debate e pensar em políticas públicas viáveis para a redução das disparidades econômicas fundadas no gênero.

Dentre as inúmeras propostas apresentadas, especificamente para as trabalhadoras domésticas remuneradas, o projeto prevê a possibilidade de dedução do imposto de renda pessoa física, das contribuições pagas a trabalhadores e trabalhadoras domésticas, bem como a dedução dos valores gastos com a educação dos descendentes diretos dos trabalhadores e trabalhadoras domésticas pagos pelos empregadores. Com essa proposta, objetiva-se estimular a contratação de mais trabalhadores domésticos remunerados, cujas mulheres são maioria, como demonstrado.

Ainda no aspecto da tributação da renda, a proposta de reforma tributária em discussão prevê políticas tributárias para estimular a contratação de mulheres chefes de família e/ou mulheres negras, além da contratação de mulheres vítimas de violência, inclusive doméstica, mediante a dedução no imposto de renda pessoa jurídica. A proposta poderia ser um incentivo à contratação de mulheres, como política afirmativa, para possibilitar o ingresso ao mercado de trabalho e, com isso, auxiliar a romper o ciclo patriarcal de trabalho doméstico não remunerado majoritariamente executado pelas mulheres.

Quanto à tributação sobre o consumo, são apontadas como propostas a desoneração de tributos federal, além da inclusão de produtos de uso majoritariamente feminino dentre os itens da cesta básica, a exemplo de absorventes íntimos, assemelhados, fraldas, infantis e geriátricas, e anticoncepcionais. Como visto, as mulheres são maioria nos trabalhos domésticos, sobretudo de cuidado de parentes, e muitas são chefes de família dos seus lares. As medidas propostas, portanto, permitem um maior acesso das mulheres aos produtos e serão essenciais para garantir 0 princípio da dignidade da pessoa humana.

Os dados e estudos apresentados sinteticamente no presente trabalho indicam um diagnóstico dos efeitos da crise econômica, política e social que o país tem 
enfrentado desde 2015, efeitos esses sentidos de maneira mais gravosa pelos segmentos sociais mais vulneráveis, com especial destaque para as mulheres que desempenham trabalho em âmbito doméstico, remunerado ou não. Todavia, tais estudam também apontam para potenciais soluções, que podem ser construídas a partir de uma política tributária que tenha como objetivo a promoção de justiça fiscal, inclusive com o viés de gênero.

\section{CONCLUSÃO}

O presente trabalho pretendeu demonstrar como as mulheres são mais impactadas pelo trabalho doméstico não remunerado e remunerado e como essa situação impacta na desigualdade econômica e de gênero. $O$ trabalho de cuidado recai mais fortemente sobre as mulheres em decorrência de uma estrutura social patriarcal e da divisão sexual do trabalho mantida pelo modelo capitalista. Para o trabalho doméstico não remunerado, sobretudo no Brasil, além da desigualdade de gênero, há um forte viés de raça e classe, sob a perspectiva das interseccionalidades.

A pandemia da COVID-19 deve acentuar ainda mais as desigualdades, razão pela qual é necessário repensar mecanismos para proteger as mulheres em situação de vulnerabilidade, reduzir as desigualdades econômicas e de gênero, e a tributação, como instrumento do qual o Estado dispõe para o financiamento das políticas públicas, vem sendo apontada como uma alternativa viável.

A Constituição Federal de 1988 (BRASIL, 1988), ao expandir as políticas públicas para a inclusão dos outsiders e ao tentar promover mudanças nos pilares do modelo conservador de política social, fez com que o Brasil reduzisse as desigualdades de 1985 a 2015. Entretanto, desde 2017, o país vem experimentando retrocessos nos projetos de redução das desigualdades sociais, processo que se coaduna com a adoção de uma fiscalidade austera.

Nesse contexto, o sistema tributário atual é regressivo, na medida em que privilegia a tributação indireta, incidente sobre produtos, bens e serviços. Para as mulheres, ainda há o agravante da incidência do fenômeno mercadológico do pink tax, pelo qual os produtos tipicamente femininos custam mais do que os masculinos, 
precificação que impacta a tributação incidente sobre o produto. Verifica-se ainda a tributação mais elevada, como itens supérfluos, para produtos de uso preponderantemente feminino, a exemplo de absorventes e bombas de amamentação, além das fraldas infantis e geriátricas, produtos extremamente atrelados ao trabalho de cuidado, ao qual, em âmbito doméstico, as mulheres são maioria.

No que diz respeito à tributação da renda, o sistema tributário nacional se desenvolveu timidamente, embora exista a previsão constitucional quanto à progressividade e necessidade de observância, sempre que possível, do princípio da capacidade contributiva. O que se observa é uma tributação mais favorecida aos rendimentos do capital em contraposição aos rendimentos do trabalho. Especificamente para as mulheres, além de receberem rendimentos inferiores aos dos homens, os seus rendimentos são mais tributados justamente em decorrência do modelo de tributação da renda adotado pelo Brasil.

Diante da crise econômica e da pandemia da COVID-19, torna-se necessário repensar o papel do Estado no enfrentamento da crise e na redução das desigualdades, inclusive de gênero. Conforme estudos demonstrados ao longo do texto, a reforma tributária é apontada como um dos mecanismos viáveis, sobretudo no que diz respeito à tributação dos super-ricos.

No Brasil, as propostas de Emenda Constitucional o 45 e 110 de 2020 sugerem a criação de um imposto único, denominado Imposto sobre Bens e Serviços (IBS), à semelhança de um Imposto sobre Valor Agregado (IVA) adotado em outros países. Contudo, os projetos objetivam alteração de competências tributárias, sem propor mecanismos para reformular o modelo atual de tributação da renda e do patrimônio.

Como contraponto, o presente trabalho trouxe, de forma sintética, alguns estudos de reforma tributária que promovam a efetiva redução das desigualdades, como o estudo "Tributar os super-ricos para o crescimento do país" (MOREIRA FILHO et al., 2020) e a proposta de reforma tributária realizada pelo grupo de pesquisas Tributação e Gênero, do Núcleo de Direito Tributário da Escola de Direito de São Paulo da Fundação Getúlio Vargas (PISCITELLI et al., 2020).

No presente trabalho, pretendeu-se demonstrar que a reformulação do sistema 
tributário é um mecanismo eficaz para tentar reduzir desigualdades, inclusive de gênero, e que urge a consecução de uma política tributária consonante ao escopo Constitucional e que promova a justiça fiscal, com a proteção de todas as mulheres, sobretudo as que exercem trabalho doméstico.

\section{REFERÊNCIAS}

AFONSO, José Roberto; LUKIC, Melina Rocha; ORAIR, Rodrigo Octávio. Tributação e desigualdade. Belo Horizonte: Letramento, 2017.

ARAÚJO, Cícero. Trinta anos depois: a crise da Constituição de 1988. Locus: Revista De História, Juíz de Fora, v. 24, n. 2, p. 299-329, 2018.

ARRETCHE, Marta. Democracia e redução da desigualdade econômica no Brasil: a inclusão dos outsiders. Revista Brasileira de Ciências Sociais, São Paulo, v. 33, n. 96, p. 1-23, 2018.

ARRIAGADA, I. Estruturas familiares, trabalho e bem-estar na América Latina. In: ARAÚJO, C.; PICANÇO, F.; SCALON, C. (org). Novas conciliações e antigas tensões?: gênero, família e trabalho em perspectiva comparada. Bauru: EDUSC, 2007. p. 223-265.

BERKHOUT, E. et al. The inequality virus: bringing together a world torn apart by coronavirus through a fair, just and sustainable economy. Oxford: OXFAM, 2021.

BIROLI, Flávia. Gênero e desigualdades: os limites da democracia no Brasil. São Paulo: Boitempo, 2018.

BRASIL. [Constituição (1988)]. Constituição da República Federativa do Brasil de 1988. Brasília, DF: Presidência da República, 1988.

BRASIL. Emenda constitucional no 72, de 2 de abril de 2013. Altera a redação do parágrafo único do art. $7^{\circ}$ da Constituição Federal para estabelecer a igualdade de direitos trabalhistas entre os trabalhadores domésticos e os demais trabalhadores urbanos e rurais. Brasília, DF: Câmara dos Deputados: Senado Federal, 2013.

Disponível em:

http://www.planalto.gov.br/ccivil_03/constituicao/emendas/emc/emc72.htm. Acesso em: 10 mar. 2021.

BRASIL. Emenda constitucional no 95, de 15 de dezembro de 2016. Altera o Ato das Disposições Constitucionais Transitórias, para instituir o Novo Regime Fiscal, e dá outras providências. Brasília, DF: Câmara dos Deputados: Senado Federal, 2013. Disponível em:

http://www.planalto.gov.br/ccivil_03/constituicao/emendas/emc/emc95.htm. Acesso em: 
10 mar. 2021.

BRASIL. Lei Complementar no 150, de 1 de junho de 2015. Dispõe sobre o contrato de trabalho doméstico; altera as Leis no 8.212, de 24 de julho de 1991, no 8.213, de 24 de julho de 1991, e no 11.196, de 21 de novembro de 2005; revoga o inciso I do art. 30 da Lei no 8.009, de 29 de março de 1990, o art. 36 da Lei no 8.213, de 24 de julho de 1991, a Lei no 5.859, de 11 de dezembro de 1972, e o inciso VII do art. 12 da Lei no 9.250, de 26 de dezembro 1995; e dá outras providências. Brasília, DF: Presidência da República, 2015. Disponível em: http://www.planalto.gov.br/ccivil_03/leis/lcp/lcp150.htm. Acesso em: 10 mar. 2021.

BRASIL. Lei no 9.249, de 26 de dezembro de 1995. Altera a legislação do imposto de renda das pessoas jurídicas, bem como da contribuição social sobre o lucro líquido, e dá outras providências. Brasília, DF: Presidência da República, 1995. Disponível em: http://www.planalto.gov.br/ccivil_03/leis/19249.htm. Acesso em: 10 mar. 2021.

CAPRARO, Chiara. Direito das mulheres e justiça fiscal: por que a política tributária deve ser tema da luta feminista. Sur, [s. I.], v. 13, n. 24, p. 17-26, 2016 . Disponível em: https://sur.conectas.org/wp-content/uploads/2017/02/1-sur-24-por-chiara-capraro.pdf. Acesso em: 22 abr. 2021.

COVID-19 acentua a situação precária de trabalhadoras e trabalhadores domésticos na América Latina e no Caribe: segundo estimativas da OIT, 70\% das trabalhadoras e dos trabalhadores domésticos na região já foram afetados por medidas tomadas para conter a pandemia. Organização Internacional do Trabalho, Lima, 2020. Disponível em: https://www.ilo.org/brasilia/noticias/WCMS_747981/lang--pt/index.htm. Acesso em: 25 mar. 2021.

CRENSHAW, Kimberlé. Documento para o encontro de especialistas em aspectos da discriminação racial relativos ao gênero. Revista Estudos Feministas, Florianópolis, v. 10, n. 1, p. 171-188, 2002. Disponível em:

http://www.scielo.br/scielo.php?script=sci_arttext\&pid=S0104-

026X2002000100011\&lng=en\&nrm=iso. Acesso em: 25 mar. 2021.

DE BLASIO, Bill; MENIN, Julie. From cradle to cane: the cost of being a female consumer: a study of gender pricing in New York City. New York: NYC Consumer Affairs, 2015. Disponível em: https://www1.nyc.gov/site/dca/partners/gender-pricing-study.page. Acesso em: 3 mar. 2021.

DIEESE. Brasil: a inserção das mulheres no mercado de trabalho. Departamento Intersindical de Estatística e Estudos Econômicos, São Paulo, 2021. Disponível em: https://www.dieese.org.br/outraspublicacoes/2021/graficosMulheresBrasilRegioes2021. html. Acesso em: 9 mar. 2021.

DOWBOR, Ladislau. Estamos precisando de uma nova economia. Jornal dos Economistas, [s. I.], n. 374, p. 12-13, 2020. 
FANDIÑO, Pedro; KERSTENETZKY, Celia Lessa. O paradoxo constitucional brasileiro: direitos sociais sob tributação regressiva. Revista de Economia Política, v. 39, n. 2, p. 306-327, 2019.

FEDERICI, Silvia. Calibã e a bruxa: mulheres corpo e acumulação primitiva. São Paulo: Elefante, 2017.

GEORGES, I. P. H.; SANTOS, Y. G. Olhares cruzados: relações de cuidado, classe e gênero: tempo Social. Revista de Sociologia da USP, São Paulo, v. 26, n. 1, p. 47-60, 2014.

GEORGIEVA, K. et al. A COVID-19 e as diferenças de gênero. International Monetary Fund, [s. I.], 2020. Disponível em: https://www.imf.org/pt/News/Articles/2020/07/20/blogthe-covid-19-gender-gap. Acesso em: 28 mar. 2021.

GOBETTI, Sérgio Wulff; ORAIR, Rodrigo Octávio. Texto para discussão 2190: progressividade tributária: a agenda negligenciada. Brasília, DF: IPEA, 2016.

GOBETTI, Sérgio Wulff; ORAIR, Rodrigo Octávio. Texto para discussão 2530: reforma tributária e federalismo fiscal: uma análise das propostas de criação de um novo imposto sobre o valor adicionado para o Brasil. Brasília, DF: IPEA, 2019.

GUTERRES, António. "Tackling the inequality pandemic: a new social contract for a new era". Africa Renewal, [s. I.], 2020. Disponível em:

https://www.un.org/africarenewal/web-features/\%E2\%80\%9Ctackling-inequalitypandemic-new-social-contract-new-era\%E2\%80\%9D. Acesso em: 28 mar. 2021.

KÜCHEMANN, Berlindes Astrid; PFEILSTICKER, Zilda Vieira de Souza. Título: cuidado com os idosos e as idosas: um trabalho feminino e precário. In: SEMINÁRIO DE TRABALHO E GÊNERO - PROTAGONISMO, ATIVISMO, QUESTÕES DE GÊNERO REVISITADAS, 4., 2012, Goiânia. Anais [...]. Goiânia: UFG, 2012. p. 1-14.

LERNER, Gerda. A criação do patriarcado: história da opressão das mulheres pelos homens. Tradução: Luiza Sellera. São Paulo: Cultrix, 2019.

LOURO, G. L. Gênero, sexualidade e educação: uma perspectiva pós-estruturalista. Petrópolis, RJ: Vozes, 1997.

MOLINA, Federico Rivas. Argentina aprova imposto sobre grandes fortunas para financiar a luta contra o coronavírus: iniciativa oficial impõe alíquota de até $3,5 \%$ a fortunas declaradas equivalentes a mais de 13 milhões de reais. EI País, Buenos Aires, 2020. Disponível em: https://brasil.elpais.com/internacional/2020-12-06/argentinaaprova-imposto-sobre-a-riqueza-para-financiar-a-luta-contra-o-coronavirus.html. Acesso em: 28 mar. 2021. 
MOREIRA FILHO, C. C. C. et al. Tributar os super-ricos para reconstruir o país: oito propostas de leis tributárias que isentam os mais pobres e as pequenas empresas, fortalecem os estados e municípios, geram acréscimo na arrecadação estimado em $\mathrm{R} \$ 292$ bilhões e incidem sobre as altas rendas e o grande patrimônio, onerando apenas os $0,3 \%$ mais ricos. [S. I.:s. n.], 2020. Disponível em: https://plataformapoliticasocial.com.br/tributar-os-super-ricos-para-reconstruir-o-pais/. Acesso em: 9 mar. 2021.

MULHERES dedicam quase o dobro do tempo dos homens em tarefas domésticas. Agência IBGE notícias, [s. I.], 2019. Disponível em: https://agenciadenoticias.ibge.gov.br/agencia-noticias/2012-agencia-denoticias/noticias/24267-mulheres-dedicam-quase-o-dobro-do-tempo-dos-homens-emtarefas-domesticas. Acesso em: 08 mar. 2021.

OLIVEIRA, Fabrício Augusto de. Uma pequena história da tributação e do federalismo fiscal no Brasil: a necessidade de uma reforma tributária justa e solidária. São Paulo: Contracorrente, 2020.

OXFAM BRASIL. País estagnado: um retrato das desigualdades brasileiras: 2018. São Paulo, SP: OXFAM BRASIL, 2020..

OXFAM BRASIL. Tempo de cuidar: o trabalho de cuidado não remunerado e mal pago e a crise global da desigualdade. [São Paulo, SP]: OXFAM BRASIL, 2020.

PETROU, llya. The pink tax: some drugs cost $40 \%$ more for women. Dermatology Times, [s. I.], v. 9, n. 38, p. 40-41, 2017.

PISCITELLI, T. et al. (coord.). Reforma tributária e desigualdade de gênero: contextualização e propostas. São Paulo: FGV, 2020. Disponível em: https://direitosp.fgv.br/sites/direitosp.fgv.br/files/arquivos/reforma_e_genero__final_1.pdf. Acesso em: 28 mar. 2021.

RIBEIRO, Ricardo Lodi. Desigualdade e tributação na era da austeridade seletiva. Rio de Janeiro: Lumen Juris, 2019.

RODRIK, Dani; STANTCHEVA, Stefanie. O contrato social pós-pandemia. ObservaBR caminhos da reconstrução e transformação do Brasil, [s. I.], 2020. Disponível em: https://fpabramo.org.br/observabr/2020/07/02/\%EF\%BB\%BFo-contrato-social-pospandemia/. Acesso em: 28 mar. 2021.

SILVA, Gustavo; TAVARES, Francisco. A ciência política brasileira diante do novo regime fiscal: para uma agenda de pesquisas sobre democracia e austeridade. DADOS, Rio de Janeiro, v. 63, n. 2, p. 1-39, 2020.

TORRES, Heleno Taveira. Desigualdade de gênero e na tributação da mulher prejudicam desenvolvimento. Revista Consultor Jurídico, [s. I.], 2019. Disponível em: 
https://www.conjur.com.br/2019-jun-12/consultor-tributario-desigualdade-tributacaomulher-prejudicam-desenvolvimento. Acesso em: 4 mar. 2021.

TRABALHADORAS domésticas fazem campanha por direitos durante a pandemia Covid-19 e articulam apoio da cooperação internacional. ONU Mulheres Brasil, [s. I.], 2020. Disponível em: https://www.onumulheres.org.br/noticias/trabalhadorasdomesticas-fazem-campanha-por-direitos-durante-a-pandemia-covid-19-e-articulamapoio-da-cooperacao-internacional/. Acesso em: 10 mar. 2021.

STOTSKY, Janet. How tax systems treat men and women differently. Finance \& Development, [s. I.], p. 30-33, 1997. Disponível em: https://www.imf.org/external/pubs/ft/fandd/1997/03/pdf/stotsky.pdf. Acesso em: 28 mar. 2021.

VILLAS BÔAS, Bruno. IBGE: salário médio das mulheres corresponde a $79,5 \%$ ao dos homens. Valor Econômico, Rio de Janeiro, 2019a. Disponível em:

https://valor.globo.com/brasil/noticia/2019/03/08/ibge-salario-medio-das-mulherescorresponde-a-795-ao-dos-homens.ghtml. Acesso em: 2o abr. 2021.

VILLAS BÔAS, Bruno. 9 milhões de mulheres viraram "chefe de família” nos últimos 7 anos. Valor Econômico, Rio de Janeiro, 2019b. Disponível em: https://valor.globo.com/brasil/noticia/2019/05/22/9-milhoes-de-mulheres-viraram-chefede-familia-nos-ultimos-7-anos.ghtml. Acesso em: 20 abr. 2021.

YAZICIOGLU, Alara Efsun. Pink tax and the law: discriminating against women consumers. London: Routledge Focus, 2018.

ZEBALLOS-ROIG, Joseph. The IMF says governments should consider new wealth taxes to raise cash from the rich as coronavirus slams the global economy. Insider, [ $s$. I.], 2020. Disponível em: https://www.businessinsider.com/governments-wealth-taxesimf-new-source-revenue-coronavirus-economy-consider-2020-4. Acesso em: 28 mar. 2021. 